\title{
AMPA receptor endocytosis in rat perirhinal cortex underlies retrieval of object memory
}

\author{
Brittany N. Cazakoff and John G. Howland ${ }^{1}$ \\ Neural Systems and Plasticity Research Group, Department of Physiology, University of Saskatchewan, Saskatoon, \\ SK S7N 3R2, Canada
}

\begin{abstract}
Mechanisms consistent with long-term depression in the perirhinal cortex (PRh) play a fundamental role in object recognition memory; however, whether AMPA receptor endocytosis is involved in distinct phases of recognition memory is not known. To address this question, we used local PRh infusions of the cell membrane-permeable Tat-GluA2 ${ }_{3 y}$ interference peptide or a scrambled control to block the endocytosis of AMPA receptors during the encoding, consolidation, or retrieval phase of object recognition memory. Tat-GluA2 ${ }_{3 Y}$ infusion before the encoding and consolidation phases did not alter recognition memory. In contrast, Tat-GluA2 ${ }_{3 Y}$ infusion prior to the retrieval phase disrupted object recognition memory. The present results indicate a distinct role for AMPA receptor endocytosis in the retrieval of visual recognition memory.
\end{abstract}

Memory for objects and events plays an integral role in how an organism experiences its environment. Such memories depend on processing in a number of brain areas, especially those of the medial temporal lobe (Squire et al. 2004). Several lines of evidence suggest that memory for previously encountered objects requires activity in the perirhinal (PRh) cortex (Brown and Aggleton 2001; Yonelinas 2001; Pihlajamaki et al. 2004; Eichenbaum et al. 2007). For example, lesions of the PRh in both primate and rodent species disrupt object recognition memory, while lesions of other areas, including the hippocampus, spare these discriminations (Meunier et al. 1993; Mumby and Pinel 1994; Ennaceur et al. 1996; Hannesson et al. 2004; Nemanic et al. 2004; Forwood et al. 2005; Winters and Bussey 2005b). As a result, understanding the neural processes in the PRh mediating recognition memory, especially in regard to the different phases of the memory process, are of considerable interest.

Mechanisms consistent with long-term depression (LTD) in the PRh are proposed to play a fundamental role in object recognition memory (Brown and Bashir 2002; Massey and Bashir 2007; Massey et al. 2008; Collingridge et al. 2010). Perirhinal neurons reduce their responsiveness following repetitive exposure to visual stimuli (Fahy et al. 1993; Zhu and Brown 1995; Xiang and Brown 1998; Brown and Bashir 2002). Long-term depression has been consistently demonstrated in PRh slices where its induction depends on several different receptor types, including NMDA receptors, metabotropic glutamate receptors (mGluR), muscarinic acetylcholine receptors (mACh), and L-type voltage-dependent calcium channels (VDCC) (Cho et al. 2000; Warburton et al. 2003; Seoane et al. 2009). Importantly, blockade of these receptor types also disrupts object recognition memory (Warburton et al. 2003; Abe et al. 2004; Winters and Bussey 2005a; Barker et al. 2006; Winters et al. 2007; Barker and Warburton 2008; Seoane et al. 2009). Recently, Griffiths and colleagues (2008) provided evidence for the involvement of AMPA receptor endocytosis in PRh-dependent object memory using an interference peptide approach. However, as their method involved a viral-mediated expression system, AMPA receptor endocytosis was blocked during the entire recognition memory test, preventing an examination

\footnotetext{
${ }^{1}$ Corresponding author.

E-mail john.howland@usask.ca.

Article is online at http://www.learnmem.org/cgi/doi/10.1101/Im.2312711.
}

of the involvement of AMPA receptor endocytosis during specific memory phases. Previous work has shown the utility of delivering interference peptides conjugated to the Tat protein either systemically or intracranially to examine the neural mechanisms underlying cognition (Collingridge et al. 2010). We chose to use the well-characterized peptide Tat-GluA2 3 (Ahmadian et al. 2004) that has been demonstrated to specifically block LTD and the regulated endocytosis of GluA2-containing AMPA receptors in a number of brain areas including the nucleus accumbens (Brebner et al. 2005), hippocampus (Fox et al. 2007), medial prefrontal cortex (Van den Oever et al. 2008), and amygdala (Kim et al. 2007). With a half-life of $\sim 4 \mathrm{~h}$, concentrations of the peptide are undetectable in the brain $24 \mathrm{~h}$ following infusion (Brebner et al. 2005). The specificity and transient action of Tat-GluA2 $2_{3 Y}$ make it suitable for the selective blockade of AMPA receptor endocytosis at discrete phases during a spontaneous recognition memory test (Fig. 1).

Adult male Long-Evans rats (Charles River Laboratories, Quebec, Canada) were paired and housed in plastic cages with food and water available ad libitum. All experimentation occurred during the light phase of a 12:12-h light/dark cycle (lights on at $0700 \mathrm{~h}$ ). Experiments were conducted in accordance with the Canadian Council on Animal Care and were approved by the University of Saskatchewan Animal Care and Use Committee. Guide cannulae $(23 \mathrm{Ga})$ were bilaterally implanted above the PRh (AP $-4.0 \mathrm{~mm}$; \pm ML 5.4; DV $-7.0 \mathrm{~mm}$ on a $10^{\circ}$ angle) (Hannesson et al. 2004). Infusion placements were confirmed using standard techniques (Fig. 1C; Hannesson et al. 2004). Obdurators (0.033-cm-diameter stainless steel wire) were inserted into each cannula to prevent blockage. Following surgery, subjects were allowed to recover for $7 \mathrm{~d}$.

All behavioral testing procedures closely followed those previously described for object recognition memory (Howland and Cazakoff 2010). Briefly, testing was conducted in a square openfield arena $(60 \mathrm{~cm} \times 60 \mathrm{~cm} \times 60 \mathrm{~cm})$ constructed of white corrugated plastic (Fig. 1A). Between trials, the arena and objects were wiped with $40 \%$ ethanol and a damp sponge. All testing was conducted between the hours of 0800 and 1200. Subjects were handled for $10 \mathrm{~min}$ per day over $3 \mathrm{~d}$ in the same procedure room used for object recognition testing. Following handling, rats were extensively habituated to the object recognition apparatus for $10 \mathrm{~min}$. In subsequent weeks, rats received one habituation session $24 \mathrm{~h}$ prior to the start of testing. 


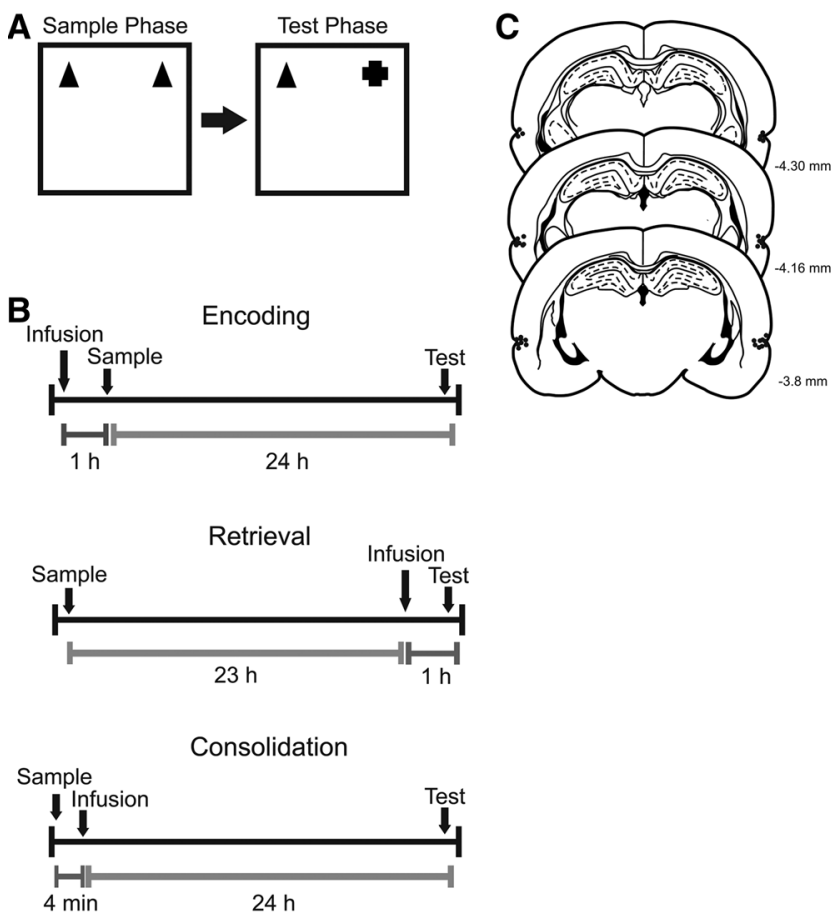

Figure 1. (A) Schematic depicting the object recognition memory test used in the present experiments. The figure depicts a bird's eye view of the open field and the arrangement of the objects for each phase. (B) Outline of the infusion times relative to the phases of the object recognition memory test. (C) Representative placements of the infusion needle tips in the PRh. Only rats with needles bilaterally positioned in the PRh were included in the study. Numbers denote the anterior-posterior position relative to the bregma.

Memory testing consisted of a sample phase and a test phase (4 min each) separated by a 24-h delay (Fig. 1A). During the sample phase, subjects were placed in the arena and allowed to explore two identical objects (A1 and A2), after which they were returned to their home cages. During the test phase, rats explored an identical copy of the sample phase object (A3) and a novel object (B1). All trials were videotaped using a camera mounted to the ceiling above the arena. Subjects were counterbalanced for sample object and for the side of the box on which the novel object was placed. Testing was conducted over multiple weeks; different object pairs were used for each week, so that rats were never exposed more than once to a specific object pair.

Subjects were separated into two groups related to the timing of the infusion: the encoding/retrieval group $(n=16)$ and the consolidation group $(n=6)$. In the encoding/retrieval group, infusions were conducted $1 \mathrm{~h}$ prior to either the sample phase or test phase (four tests) (Fig. 1B). Every rat was subjected to the four different drug/infusion time parameters (control sample infusion, control test infusion, peptide sample infusion, peptide test infusion). In the consolidation group, infusions were conducted immediately following the sample phase (early consolidation; two tests: control, peptide infusion) (Fig. 1B). Rats were habituated to the infusion procedure as described previously (Hannesson et al. 2004). For infusions, a needle (30 Ga stainless steel) connected via PE-50 tubing to the infusion pump was inserted into each cannula and $1 \mu \mathrm{L}(0.5 \mu \mathrm{L} / \mathrm{min} ; 40 \mathrm{ng} / \mu \mathrm{L})$ of either Tat-GluA2 $2_{3 Y}$ (YGRKKRRQRRR- ${ }^{869}$ YKEGYNVYG ${ }^{877}$ ) or scrambled peptide (YGRKKRRQRRR-VYKYGGYNE) was delivered into the PRh. Peptides were purchased from GL Biochem Ltd. Previous studies using lidocaine suggest that this volume will affect tissue $0.8-1.3 \mathrm{~mm}$ from the infusion site corresponding to areas 35 and 36 of the PRh (Seamans et al. 1995; Tehovnik and Sommer 1997; Hannesson et al. 2004). In some rats, needles were inserted, but no peptide was delivered. The infusion needles were left in place for an additional minute following the infusion to allow for diffusion, after which rats were returned to their home cages.

Data were scored according to measures previously described (Howland and Cazakoff 2010). Total exploration times of the objects on a given trial and discrimination ratios (DR), calculated as (time exploring the novel object - time exploring the familiar object)/total time exploring both objects, were quantified for each rat. Previous studies suggest that 2 min may be the ideal length for the test trial in a spontaneous object recognition memory paradigm, as novel object preference is reduced after that time (Dix and Aggleton 1999; Clark et al. 2000; Barker et al. 2007). Given this, we also restricted our analysis to the first 2 min of the test phase. In the consolidation experiment, the data from one animal in the control were removed from the group due to an extremely low DR $(-0.46)$, and these data were replaced with the group mean. Analysis showed no order effects of TatGluA2 3 infusions, or repeated testing (data not shown). Total exploration times for each test were analyzed using repeatedmeasures ANOVA. For test phase data, the DR for each group was analyzed using one sample $t$-tests (with a comparison value of 0 indicating chance performance), while comparisons between treatments were performed using two-way repeated-measures ANOVA (encoding/retrieval group) or paired sample $t$-tests (consolidation group). Post-hoc comparisons were made using paired t-tests with a Bonferroni correction (Hannesson et al. 2004). A $P$-value of $<0.05$ was considered significant for all statistical tests.

Total exploration times are summarized in Table 1 . No significant differences between treatment groups were noted for the encoding/retrieval group (statistics not shown). For the consolidation group, a repeated- measures ANOVA revealed a significant effect of Phase $\left(F_{(1,5)}=8.096, P=0.017\right)$ but no other significant effects. Inspection of the data revealed that regardless of treatment, subjects explored the objects significantly less during the test phase $(29.95 \pm 2.14 \mathrm{sec})$ than the sample phase $(39.03 \pm$ $3.94 \mathrm{sec})$.

Figure 2A displays the DR calculated over 4 min of exploration for treatment groups infused before the sample phase (encoding) or before the test phase (retrieval). Animals receiving a control or scrambled peptide infusion before either the sample or test phases showed robust recognition memory (presample: $t_{(15)}=5.75, P<0.001$; pretest: $\left.t_{(15)}=4.58, P<0.001\right)$. When the rats were infused with the Tat-GluA2 $2_{3 y}$ peptide prior to the sample phase, memory remained intact and at a level comparable to the control groups $\left(t_{(15)}=4.21, P=0.001\right)$ In dramatic contrast, Tat-GluA2 3 infusion prior to the retrieval phase disrupted memory for the previously encountered object as the rats did

Table 1. Total exploration time of both objects ( $\mathrm{s} \pm$ standard error of the mean) in the 4-min sample and 4- and 2-min test phases

\begin{tabular}{|c|c|c|c|}
\hline $\begin{array}{l}\text { Treatment- } \\
\text { infusion time }\end{array}$ & $\begin{array}{l}\text { Sample phase } \\
\text { (4 min) }\end{array}$ & $\begin{array}{l}\text { Test phase } \\
\text { (4 min) }\end{array}$ & $\begin{array}{l}\text { Test phase } \\
(2 \mathrm{~min})\end{array}$ \\
\hline Ctrl presample & $35.53 \pm 3.24$ & $35.43 \pm$ & $23.53=$ \\
\hline Ctrl & & & \\
\hline Ctrl post-sample & $38.08 \pm 3.64$ & $30.26 \pm 3.29$ & $19.68 \pm 2.24$ \\
\hline Pep presample & $36.48 \pm 2.4$ & $36.35 \pm 3.70$ & $21.84 \pm 2.51$ \\
\hline Pep pretest & $40.21 \pm 3.94$ & & $19.62 \pm 1.56$ \\
\hline Pep post-sample & $39.99 \pm 6.99$ & $29.64 \pm 2.77$ & $16.33 \pm 2.66$ \\
\hline
\end{tabular}

(Ctrl) Sham and scrambled peptide infused rats, (Pep) Tat-GluA2 $2_{3 y}$ peptidetreated rats. 

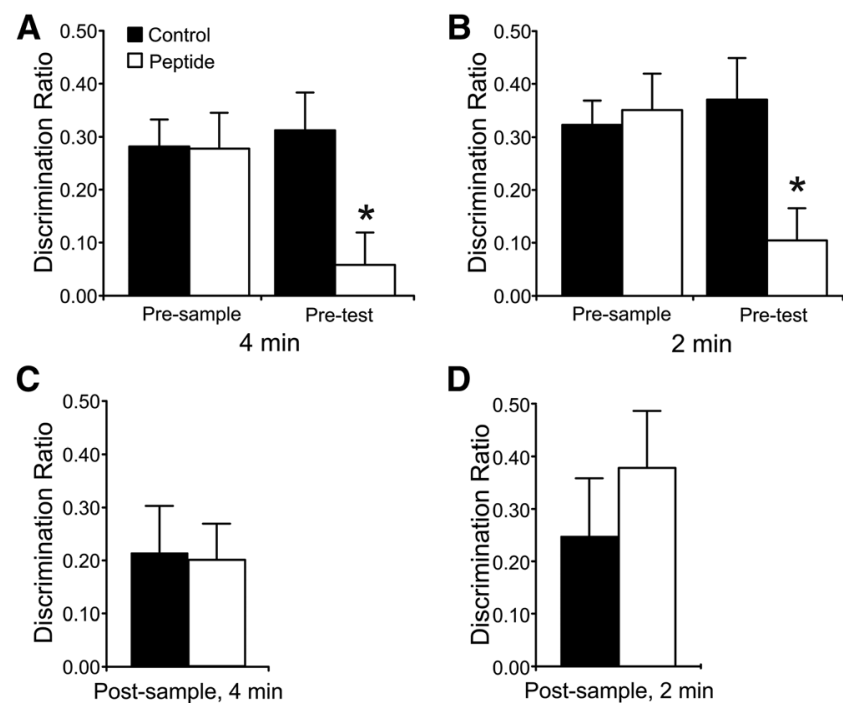

D

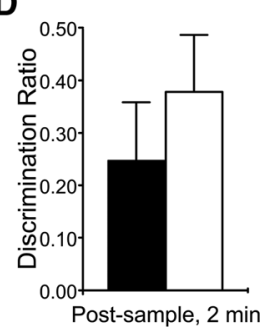

Figure 2. The effects of blocking AMPA receptor endocytosis object recognition memory. Because novel objects may become familiar with increased exploration time, data were analyzed both during the entire $4 \mathrm{~min}$ and the first $2 \mathrm{~min}$ of test exploration. Infusion of the Tat-GluA2 $2_{3 Y}$ peptide prior to the test but not the sample phase disrupts memory during $4 \mathrm{~min}(A)$ or the first $2 \mathrm{~min}(B)$ of the test phase. Infusion of the Tat-GluA ${ }_{3 y}$ peptide immediately following the sample phase did not influence memory for the previously encountered object when either $4 \mathrm{~min}$ $(C)$ or the first $2 \mathrm{~min}(D)$ of the test trial were considered. Data are displayed as the mean discrimination ratio \pm the standard error of the mean. Asterisks denote significant differences from all other groups.

not show a preference for the novel object $\left(t_{(15)}=0.97, P=0.39\right)$. A repeated-measures ANOVA revealed no significant main effect of Infusion Time $\left(F_{(1,15)}=2.05, P=0.17\right)$ or Treatment $\left(F_{(1,15)}=\right.$ $2.99, P=0.10)$ but a significant Infusion Time by Treatment interaction $\left(F_{(1,15)}=5.71, P=0.03\right)$. Post-hoc analysis revealed that the preretrieval Tat-GluA2 3 group displayed significantly lower discrimination than all other groups $(P<0.05)$. Consistent with the results from the 4-min analysis, memory during the first 2 min of the test phase was intact for all animals except for those receiving Tat-GluA2 $2_{3 \mathrm{Y}}$ infusion at retrieval (statistics not shown) (Fig. 2B).

Tat-GluA2 $2_{3 Y}$ infusions immediately following the sample trial (early consolidation) failed to significantly affect memory when either $4 \min \left(t_{(5)}=0.01, P=0.91\right)$ (Fig. 2C) or $2 \min \left(t_{(5)}=\right.$ $1.68, P=0.25$ ) (Fig. 2D) of the test phase were analyzed. One-sample $t$-tests revealed that control rats showed DRs significantly above chance when $2 \mathrm{~min}$ (control: $t_{(5)}=2.44, P=0.029$ ) or 4 min (control: $t_{(5)}=2.56, P=0.025$ ) of the test trial were considered. The DR of Tat-GluA $2_{3 \mathrm{Y}}$-treated rats was significantly above chance during the first $2 \mathrm{~min}$ of the test phase $\left(t_{(5)}=3.84, P=\right.$ $0.012)$ but not if all 4 min were considered $\left(t_{(5)}=1.54, P=0.18\right)$.

The present study examined the role of AMPA receptor endocytosis in the encoding, consolidation, and retrieval of object recognition memory. Using intra-PRh microinfusions of the Tat-GluA2 $2_{3 Y}$ interference peptide which disrupts the regulated endocytosis of GluA2-containing AMPA receptors, we transiently and specifically blocked AMPA receptor endocytosis during these three discrete phases of memory (Fig. 1). The results indicate a distinct role for AMPA receptor endocytosis in the PRh during the retrieval but not the encoding or early consolidation of the memory (Fig. 2).

The spontaneous object recognition memory test used in the present experiments is a well-established assay for examining recognition memory in rodents (Ennaceur and Delacour 1988). It is particularly suitable for examining the neural mechanisms of memory, as confounds related to reward or extensive rule learning are minimized. In both experiments, a repeated-measures design was implemented as is common in studies using the spontaneous object recognition memory test (Hannesson et al. 2004; Winters and Bussey 2005a). In the first experiment, total exploration times for the sample and test phases did not differ among groups (Table 1). In the second experiment, rats in both treatment groups displayed lower total exploration times during the test phase than during the sample phase when all 4 min were considered but not when the first 2 min were considered. While it is not clear why total exploration was reduced during the second half of the test trial for these rats, it may be accounted for by short-term habituation to the objects and recognition task over a test day (Howland and Cazakoff 2010). Importantly, lower exploration during the test trial was observed in both the control and Tat-GluA2 3 -treated animals, indicating that infusion of the peptide was not responsible for this effect. These data suggest that the observed disruption of memory retrieval following Tat-GluA2 $3 \mathrm{Y}$ infusion cannot be attributed to a nonspecific effect of the Tat-GluA2 $2_{3 y}$ peptide on exploration or general motor activity.

To our knowledge, this is the first study demonstrating a pharmacological disruption of PRh-dependent object recognition memory specific to the retrieval phase. Using a different interference peptide, Griffiths et al. (2008) provide direct evidence supporting the role of AMPA receptor endocytosis in object recognition memory. The peptide ( $\triangle \mathrm{A} 843-\mathrm{Q} 853$ or G2CT) is also derived from a short section of the carboxyl tail of the GluA2 subunit and blocks the interaction of AMPA receptors with the clathrin adaptor protein AP2 (Lee et al. 2002; Collingridge et al. 2010). Intra-PRh expression of the $\Delta A 843-Q 853$ peptide disrupted object recognition memory at delays of $5 \mathrm{~min}$ and $24 \mathrm{~h}$. However, the lentiviral expression system used to express the peptide does not have the temporal specificity necessary to examine the effects of the peptide during the different phases of memory. Our present results support the assertion that the GluA2-subunit-containing AMPA receptor endocytosis in the $\mathrm{PRh}$ is specifically required for the retrieval of object recognition memory.

The highly selective action of the Tat-GluA2 3 Y and $\Delta$ A843Q853 peptides in blocking the regulated endocytosis of GluA2containing AMPA receptors (Lee et al. 2002; Ahmadian et al. 2004; Collingridge et al. 2010) suggests that mechanisms consistent with synaptic weakening or LTD in the PRh are involved in recognition memory retrieval. Long-term depression in the PRh has been hypothesized to be critical for PRh-dependent object recognition memory (Brown and Bashir 2002; Massey and Bashir 2007; Massey et al. 2008; Collingridge et al. 2010), and several lines of evidence in rodents and primates support this hypothesis. Neurons in PRh slices demonstrate a propensity for LTD upon lowfrequency stimulation (Cho et al. 2000; Warburton et al. 2003; Griffiths et al. 2008; Seoane et al. 2009). In vivo electrophysiological studies have shown that upon the second, but not first, exposure to a stimulus, single neuron responses in the PRh display attenuated responding in monkeys and anesthetized rats (Fahy et al. 1993; Zhu and Brown 1995; Xiang and Brown 1998). Activation of PRh neurons, as assayed by c-fos expression, is also reduced upon repeated exposure to familiar pictures (Zhu et al. 1995; Seoane et al. 2009). Similarly, the test trial used in the present study also involves presentation of one copy of the familiar object and a novel object (Fig. 1). Thus, it is possible that re-exposure to a familiar stimulus may be the trigger for AMPA receptor endocytosis.

While it is tempting to speculate that the results of the study by Griffiths et al. (2008) and the present experiments are congruent, some unresolved issues exist. Most importantly, the upstream regulators resulting in the endocytosis of AMPA receptors during 
the retrieval of object memory are unknown. Electrophysiological recordings from slices have shown that NMDA receptors, group I and II mGluRs, muscarinic acetylcholine receptors, and L-type VDCCs are required for LTD induction in the PRh (Cho et al. 2000; Warburton et al. 2003; Massey et al. 2004; Seoane et al. 2009), and the possibility exists that Tat-GluA2 $2_{3 Y}$ disrupts the AMPA receptor-dependent expression of LTD following activation of one or a combination of these receptors types. Specifically, both the Tat-GluA2 $2_{3 Y}$ and $\Delta$ A843-Q853 peptides have been demonstrated to block NMDA receptor-dependent LTD in a number of brain areas including the PRh (Griffiths et al. 2008; Collingridge et al. 2010). However, blockade of NMDA receptors in the PRh prior to or immediately after encoding, but not prior to retrieval, disrupts object recognition (Abe et al. 2004; Winters and Bussey 2005a). Similarly, group I and II mGluR or cholinergic antagonists disrupt object memory when given prior to encoding but are without effect when delivered prior to retrieval (Warburton et al. 2003; Barker et al. 2006). These findings provide correlational support for the role of LTD in the encoding of object recognition memory. However, in addition to their role in LTD, membrane receptors are involved in numerous excitatory and synaptic processes (Ferraguti and Shigemoto 2006; Rebola et al. 2010; Nicoletti et al. 2011). The possibility exists that blocking these receptors prior to the sample phase not only disrupts LTD but also other signaling functions of the receptors, resulting in the observed memory deficits (Collingridge et al. 2010). Consistent with this assertion is data demonstrating that the blockade of AMPA receptors with CNQX during either encoding, consolidation, or retrieval impairs object recognition memory (Winters and Bussey 2005a), while L-type VDCC antagonists such as verapamil or diltiazem disrupt object recognition memory (24-h delay) when administered at either encoding or retrieval (Seoane et al. 2009). Given that none of the receptors discussed above (NMDA, AMPA, mGluR, acetylcholine, or L-type VDCC) have specific roles in only the retrieval of object recognition memory, future experiments will be necessary to determine the upstream regulators of AMPA receptor endocytosis. AMPA receptor endocytosis requires a complicated series of intracellular events that are specific to the induction trigger (Collingridge et al. 2004, 2010). Phosphorylation of the tyrosine residues located in the region of the GluA2 subunit mimicked by the GluA2 $2_{3 Y}$ peptide is one event necessary for the regulated endocytosis of GluA2-containing AMPA receptors (Ahmadian et al. 2004; Hayashi and Huganir 2004), although it may not be sufficient (Hayashi and Huganir 2004). Examination of the role of kinases such as those from the SRC family (Hayashi and Huganir 2004) may clarify the upstream signaling events that cause GluA2-containing AMPA receptor endocytosis during object recognition memory retrieval.

In summary, these results further support the critical role of mechanisms consistent with LTD in the PRh for object recognition memory. The present report demonstrates GluA2-containing AMPA receptor endocytosis is involved in the retrieval of object recognition memory but not in the initial encoding or consolidation. Taken together, these results suggest that depressed neural responding in perirhinal neurons following reintroduction to familiar stimuli involves the removal of AMPA receptors from the synaptic cleft.

\section{Acknowledgments}

This work was supported by a Discovery Grant from the Natural Sciences and Engineering Research Council of Canada (NSERC), a 2009 Young Investigator Award from the National Alliance for Research on Schizophrenia and Depression, and a Saskatchewan Health Research Foundation New Investigator Award to J.G.H. B.N.C. is the recipient of an NSERC Canada Graduate
Scholarship. The authors wish to thank E. Froc, Q. Greba, N. Kulhmann, and S. Gryba for technical assistance.

\section{References}

Abe H, Ishida Y, Iwasaki T. 2004. Perirhinal N-methyl-D-aspartate and muscarinic systems participate in object recognition in rats. Neurosci Lett 356: 191-194.

Ahmadian G, Ju W, Liu L, Wyszynski M, Lee SH, Dunah AW, Taghibiglou C, Wang Y, Lu J, Wong TP, et al. 2004. Tyrosine phosphorylation of GluR2 is required for insulin-stimulated AMPA receptor endocytosis and LTD. EMBO J 23: $1040-1050$.

Barker GR, Warburton EC. 2008. NMDA receptor plasticity in the perirhinal and prefrontal cortices is crucial for the acquisition of long-term object-in-place associative memory. J Neurosci 28: 2837-2844.

Barker GR, Bashir ZI, Brown MW, Warburton EC. 2006. A temporally distinct role for group I and group II metabotropic glutamate receptors in object recognition memory. Learn Mem 13: 178-186.

Barker GR, Bird F, Alexander V, Warburton EC. 2007. Recognition memory for objects, place, and temporal order: A disconnection analysis of the role of the medial prefrontal cortex and perirhinal cortex. J Neurosci 27: 2948-2957.

Brebner K, Wong TP, Liu L, Liu Y, Campsall P, Gray S, Phelps L, Phillips AG, Wang YT. 2005. Nucleus accumbens long-term depression and the expression of behavioral sensitization. Science 310: 1340-1343.

Brown MW, Aggleton JP. 2001. Recognition memory: What are the roles of the perirhinal cortex and hippocampus? Nat Rev Neurosci 2: 51-61.

Brown MW, Bashir ZI. 2002. Evidence concerning how neurons of the perirhinal cortex may effect familiarity discrimination. Philos Trans $R$ Soc Lond B Biol Sci 357: 1083-1095.

Cho K, Kemp N, Noel J, Aggleton JP, Brown MW, Bashir ZI. 2000. A new form of long-term depression in the perirhinal cortex. Nat Neurosci 3: $150-156$.

Clark RE, Zola SM, Squire LR. 2000. Impaired recognition memory in rats after damage to the hippocampus. J Neurosci 20: $8853-8860$.

Collingridge GL, Isaac JT, Wang YT. 2004. Receptor trafficking and synaptic plasticity. Nat Rev Neurosci 5: 952-962.

Collingridge GL, Peineau S, Howland JG, Wang YT. 2010. Long-term depression in the CNS. Nat Rev Neurosci 11: 459-473.

Dix SL, Aggleton JP. 1999. Extending the spontaneous preference test of recognition: Evidence of object-location and object-context recognition. Behav Brain Res 99: 191-200.

Eichenbaum H, Yonelinas AP, Ranganath C. 2007. The medial temporal lobe and recognition memory. Annu Rev Neurosci 30: 123-152.

Ennaceur A, Delacour J. 1988. A new one-trial test for neurobiological studies of memory in rats. 1: Behavioral data. Behav Brain Res 31: 47-59.

Ennaceur A, Neave N, Aggleton JP. 1996. Neurotoxic lesions of the perirhinal cortex do not mimic the behavioral effects of fornix transection in the rat. Behav Brain Res 80: 9-25.

Fahy FL, Riches IP, Brown MW. 1993. Neuronal activity related to visual recognition memory: Long-term memory and the encoding of recency and familiarity information in the primate anterior and medial inferior temporal and rhinal cortex. Exp Brain Res 96: 457-472.

Ferraguti F, Shigemoto R. 2006. Metabotropic glutamate receptors. Cell Tissue Res 326: 483-504.

Forwood SE, Winters BD, Bussey TJ. 2005. Hippocampal lesions that abolish spatial maze performance spare object recognition memory at delays of up to 48 hours. Hippocampus 15: 347-355.

Fox CJ, Russell K, Titterness AK, Wang YT, Christie BR. 2007. Tyrosine phosphorylation of the GluR2 subunit is required for long-term depression of synaptic efficacy in young animals in vivo. Hippocampus 17: $600-605$.

Griffiths S, Scott H, Glover C, Bienemann A, Ghorbel MT, Uney J, Brown MW, Warburton EC, Bashir ZI. 2008. Expression of long-term depression underlies visual recognition memory. Neuron 58: 186-194.

Hannesson DK, Howland JG, Phillips AG. 2004. Interaction between perirhinal and medial prefrontal cortex is required for temporal order but not recognition memory for objects in rats. J Neurosci 24: 4596-4604.

Hayashi T, Huganir RL. 2004. Tyrosine phosphorylation and regulation of the AMPA receptor by SRC family tyrosine kinases. J Neurosci $\mathbf{2 4 :}$ $6152-6160$.

Howland JG, Cazakoff BN. 2010. Effects of acute stress and GluN2Bcontaining NMDA receptor antagonism on object and object-place recognition memory. Neurobiol Learn Mem 93: 261-267.

Kim J, Lee S, Park K, Hong I, Song B, Son G, Park H, Kim WR, Park E, Choe HK, et al. 2007. Amygdala depotentiation and fear extinction. Proc Natl Acad Sci 104: 20955-20960.

Lee SH, Liu L, Wang YT, Sheng M. 2002. Clathrin adaptor AP2 and NSF interact with overlapping sites of GluR2 and play distinct roles in AMPA receptor trafficking and hippocampal LTD. Neuron 36: 661-674. 
Massey PV, Bashir ZI. 2007. Long-term depression: Multiple forms and implications for brain function. Trends Neurosci 30: 176-184.

Massey PV, Johnson BE, Moult PR, Auberson YP, Brown MW, Molnar E, Collingridge GL, Bashir ZI. 2004. Differential roles of NR2A and NR2B-containing NMDA receptors in cortical long-term potentiation and long-term depression. J Neurosci 24: 7821-7828.

Massey PV, Phythian D, Narduzzo K, Warburton EC, Brown MW, Bashir ZI. 2008. Learning-specific changes in long-term depression in adult perirhinal cortex. J Neurosci 28: 7548-7554.

Meunier M, Bachevalier J, Mishkin M, Murray EA. 1993. Effects on visual recognition of combined and separate ablations of the entorhinal and perirhinal cortex in rhesus monkeys. J Neurosci 13: 5418-5432.

Mumby DG, Pinel JP. 1994. Rhinal cortex lesions and object recognition in rats. Behav Neurosci 108: $11-18$.

Nemanic S, Alvarado MC, Bachevalier J. 2004. The hippocampal/ parahippocampal regions and recognition memory: Insights from visual paired comparison versus object-delayed nonmatching in monkeys. J Neurosci 24: 2013-2026.

Nicoletti F, Bockaert J, Collingridge GL, Conn PJ, Ferraguti F, Schoepp DD, Wroblewski JT, Pin JP. 2011. Metabotropic glutamate receptors: From the workbench to the bedside. Neuropharmacology 60: 1017-1041.

Pihlajamaki M, Tanila H, Kononen M, Hanninen T, Hamalainen A, Soininen H, Aronen HJ. 2004. Visual presentation of novel objects and new spatial arrangements of objects differentially activates the medial temporal lobe subareas in humans. Eur J Neurosci 19: 1939-1949.

Rebola N, Srikumar BN, Mulle C. 2010. Activity-dependent synaptic plasticity of NMDA receptors. J Physiol 588: 93-99.

Seamans JK, Floresco SB, Phillips AG. 1995. Functional differences between the prelimbic and anterior cingulate regions of the rat prefrontal cortex. Behav Neurosci 109: 1063-1073.

Seoane A, Massey PV, Keen H, Bashir ZI, Brown MW. 2009. L-type voltage-dependent calcium channel antagonists impair perirhinal long-term recognition memory and plasticity processes. J Neurosci 29: 9534-9544.

Squire LR, Stark CE, Clark RE. 2004. The medial temporal lobe. Annu Rev Neurosci 27: 279-306.
Tehovnik EJ, Sommer MA. 1997. Effective spread and time course of neural inactivation caused by lidocaine injection in monkey cerebral cortex. $J$ Neurosci Methods 74: 17-26.

Van den Oever MC, Goriounova NA, Li KW, Van der Schors RC, Binnekade R, Schoffelmeer AN, Mansvelder HD, Smit AB, Spijker S, De Vries TJ. 2008. Prefrontal cortex AMPA receptor plasticity is crucial for cue-induced relapse to heroin-seeking. Nat Neurosci 11: 1053-1058.

Warburton EC, Koder T, Cho K, Massey PV, Duguid G, Barker GR, Aggleton JP, Bashir ZI, Brown MW. 2003. Cholinergic neurotransmission is essential for perirhinal cortical plasticity and recognition memory. Neuron 38: 987-996.

Winters BD, Bussey TJ. 2005a. Glutamate receptors in perirhinal cortex mediate encoding, retrieval, and consolidation of object recognition memory. J Neurosci 25: 4243-4251.

Winters BD, Bussey TJ. 2005b. Transient inactivation of perirhinal cortex disrupts encoding, retrieval, and consolidation of object recognition memory. J Neurosci 25: 52-61.

Winters BD, Bartko SJ, Saksida LM, Bussey TJ. 2007. Scopolamine infused into perirhinal cortex improves object recognition memory by blocking the acquisition of interfering object information. Learn Mem 14: $590-596$

Xiang JZ, Brown MW. 1998. Differential neuronal encoding of novelty, familiarity, and recency in regions of the anterior temporal lobe. Neuropharmacology 37: 657-676.

Yonelinas AP. 2001. Components of episodic memory: The contribution of recollection and familiarity. Philos Trans R Soc Lond B Biol Sci 356: $1363-1374$.

Zhu XO, Brown MW. 1995. Changes in neuronal activity related to the repetition and relative familiarity of visual stimuli in rhinal and adjacent cortex of the anaesthetised rat. Brain Res 689: 101-110.

Zhu XO, Brown MW, McCabe BJ, Aggleton JP. 1995. Effects of the novelty or familiarity of visual stimuli on the expression of the immediate early gene c-fos in rat brain. Neuroscience 69: 821-829.

Received June 14, 2011; accepted in revised form August 24, 2011. 


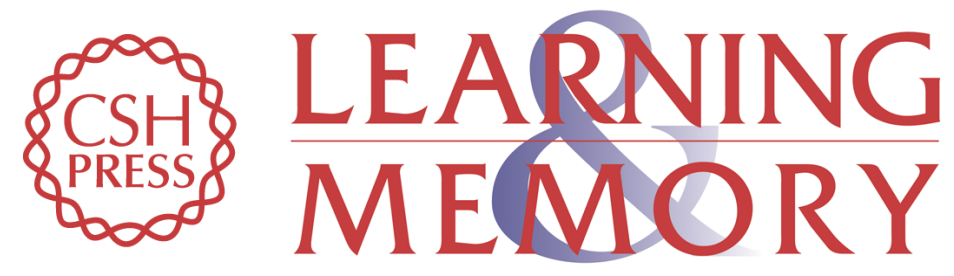

\section{AMPA receptor endocytosis in rat perirhinal cortex underlies retrieval of object memory}

Brittany N. Cazakoff and John G. Howland

Learn. Mem. 2011, 18:

Access the most recent version at doi:10.1101/lm.2312711

References This article cites 48 articles, 16 of which can be accessed free at: http://learnmem.cshlp.org/content/18/11/688.full.html\#ref-list-1

License

Email Alerting Receive free email alerts when new articles cite this article - sign up in the box at the Service top right corner of the article or click here. 